\title{
Using Virtual Reality (VR) in Teaching Students With Dyslexia
}

$\underline{\text { https://doi.org/10.3991/ijet.v16i09.19653 }}$

\author{
Esraa Maskati ${ }^{\bowtie}$, Fatimah Alkeraiem, Nada Khalil, \\ Raha Baik, Rawan Aljuhani \\ Taibah University, Medina, Saudi Arabia \\ esraa.1695@gmail.com
}

Aisha Alsobhi

King Abdulaziz University, Jeddah, Saudi Arabia

\begin{abstract}
Studies show that the number of dyslexic students is increasing, as it does the need of the appropriate learning techniques and methodologies increases as well. For the students with learning disability, generally and the dyslexic students specifically there aren't enough technologies that helps them in the learning process. Not only the students with learning disability face this problem but parents and teachers are involved as well. The challenge that students with dyslexia face is that they find difficulties in processing and remembering information, so they need extra effort and time to learn especially when learning the basics like alphabets. In order to help students' teachers and parents in the learning process, we developed methodology that mixes education with entertainment and produces an effective way of teaching. The proposed application teaches the students the alphabet by tracing the Arabic letters in the three forms initial, middle and final form, and pronounce the letters as well. It uses a friendly virtual reality environment. Virtual reality VR is one of the latest techniques in both education and entertainment which proved its effectiveness. It motivates the students to learn, interact and make the learning processes more productive. The aim of this research is to help the dyslexic students, teachers and parents to learn and enhance the learning process. The evaluation of the system revealed that the proposed application successfully supported students learning in general and students with dyslexia specifically.
\end{abstract}

\section{Keywords - Virtual Reality; Dyslexia; Learning Disability; Avatar}

\section{$1 \quad$ Introduction}

Daily, teachers strive to find an optimal learning technique that meets students' individual differences. However, while such technologies are promising, they are also evolving at a rapid pace. The educators and students are faced with several significant challenges due to this rapid pace [1]. Most of these techniques fail to consider the specific needs of an important group of the community, which are the students with learning disabilities (LDs) [2,3]. The research described in this paper examines the 
impact of the use of technology in the classroom setting on educational outcomes with a specific focus on Primary school students with the learning disability which is Dyslexia.

The UK Department of Health has defined a learning disability as a "significant reduced ability to understand new or complex information, to learn new skills, with a reduced ability to cope independently, which started before adulthood" [4].

Dyslexia is a learning disability and a life-long condition that is described as a specific reading and writing difficulties $[5,6]$. Dyslexia is a very complicated and multifaceted condition that affects sufferers in many ways. Rarely, two people with dyslexia will typically encounter the same symptoms [7,8]. This basic fact is at the core of this current research. However, a student with some dyslexia generally tends to find difficulty processing and remembering information they see, hear, and take longer to learn certain life skills such as reading, writing and speaking [9]. They may also need help in developing new skills, connecting information and interacting with other people.

Dyslexia has been the subject of significant research, and various definitions of the condition have emerged over the years. In 2007, the management board of the British Dyslexia Association developed the following definition of dyslexia:

Dyslexia is a specific learning difficulty that mainly affects the development of literacy and language related skills.

It is likely to be present at birth and to be life-long in its effects. It is characterized by difficulties with phonological processing, rapid naming, working memory, processing speed, and the automatic development of skills that may not match up to an individual's other cognitive abilities.

It tends to be resistant to conventional teaching methods, but its effect can be mitigated by appropriately specific intervention, including the application of information technology and supportive counselling.

While variations in understanding of dyslexia are fully acknowledged, for the purpose of this research, an educational perspective of dyslexia will be applied. As such, the definition suggested by the British Dyslexia Association (BDA) will be considered in this research. It is anticipated that this definition represents a strong fit with the objectives of this research because it is not limited to children alone; rather, it has been specifically developed from an educational point of view and covers different types of dyslexia.

The increased use of ICTs by means of assistive technologies (ATs) has provided mechanisms through which students who have disabilities can access some of the learning experiences that are available to their peers. For example, chat-based programs have provided deaf children with a chance to communicate with others, text-tospeech tools have allowed children who are blind to access the content of books and stories, and word processing applications and their accompanying grammar and spelling checks have helped dyslexic students to overcome their disabilities.

The main aim of this project is to develop a graphical application, which in turn will develop and improve the primary school dyslexic students writing and reading by using the advantages of Virtual Reality (VR) environment and avatars to guide children through the learning process. 
The following subsections will examine the rationale that underpins this research and will provide further information about the research objectives, and the contribution it can make to improve the educational outcomes for dyslexic students.

\section{Problem Rationale}

Life skills such as reading, writing and speaking approach already exists as applications within the educational context but it does not meet that the needs of students with dyslexia as well as it does not support multiple languages such as the Arabic Language.

Dyslexia is extremely complex and multifaceted and, as such, it is extremely difficult to develop a standard system that is capable of meeting the unique and varied needs of a wide range of disabled users [10]. Many of the e-learning tools that are currently in use in the classroom setting present the same problems to dyslexic learners as more traditional paper-based approaches. The text-based synchronous activities that are commonly employed within the classroom setting, can serve to disadvantage students who have conditions like dyslexia [11]. Many researchers think of dyslexia as reading difficulties and ignore the other difficulties. The focus of the current research is children with dyslexia.

The students nowadays interact with the technology-based approach more than the traditional ways. They also understand better when the learning process is supported with any forms of multimedia such as Avatar, Virtual Environment and images. This in line with what Aristotle once said, "The soul never thinks without a mental image". Multimedia not only improves memory and recollection but also helps the student comprehend and process information easily and increases their engagement.

\subsection{Research objectives, and contribution}

The proposed application is provided with the VR headset feature, along with an "avatar" feature. The avatar feature will guide the students and help them to use the application properly rather than just a plain text. Hence, increase the students' engagement. Moreover, most of dyslexia applications available in the market are not free and could be expensive. Hence, one of our motivations is to develop a free application for dyslexic learners that will help the students and their families in developing their language skills. In addition, available dyslexia apps do not support Arabic language. They may not be appropriate to be used for Arabic learners due to some culture aspects. Therefore, this application will support Arabic language unlike other language skills applications hence suits our culture.

The proposed application is built for an educational purpose and will support the Arabic language. It addresses the writing skills for student with dyslexia in primary school but can be used at home as a tool to enhance learning experience. The Application is based on the mobile phones with VR Headset. It is designed to help students in general but addresses the needs of a student with dyslexic in specific. 
- This application is a new service for Primary school dyslexic students to learn new concepts. In addition to, how to write and learn alphabets.

- This application helps dyslexic students to differentiate between forms of the Arabic alphabets letter and comprehend information.

- The application will give some visual instructions by using avatar.

- Dyslexic students can write alphabet and words by themselves, due to the existing of Visual instructions and user-friendly interface.

- Students that do not have a learning disability can use the application in order to increase their engagement and motivation.

This project proposes a simple and portable solution for students with dyslexia in Primary school to overcome their disability. It also offers to do so in Arabic language. The research will make a valuable contribution to the education and technology fields in the following ways:

- According to our research, there isn't any educational application that is specialized in teaching Arabic alphabets for dyslexic students by using the VR technology. Therefore, this project will use the VR headset with a 3D graphical environment to teach the students with dyslexia the Arabic letters with more interactive and fun way.

- The application is designed for primary school dyslexic students to learn Arabic skills.

- The avatar works as guidance from the student when needed. The avatar reads the letter after the student selects it.

- The combination of VR and Avatar considered as a novel contribution of this project.

- The dyslexic students can differentiate between the Arabic alphabet letter in its different forms.

\section{Dyslexia}

\subsection{What is dyslexia?}

In 1968, the World Federation of Neurology published one of the first formally recognised definitions of dyslexia. This was as follows: a disorder in children who, despite conventional classroom experience, fail to attain the language skills of reading, writing and spelling commensurate with their intellectual abilities [12]. The definition forwarded by the [13] is more specific:

Dyslexia is a specific learning disability that is neurological in origin. It is characterised by difficulties with accurate and/or fluent word recognition and by poor spelling and decoding abilities. These difficulties typically result from a deficit in the phonological component of language that is often unexpected in relation to other cognitive abilities and the provision of effective classroom instruction. Secondary consequences may include problems in reading comprehension and reduced reading experience that can impede the growth of vocabulary and background knowledge. 
The British Dyslexia Association (BDA) says: Dyslexia is best described as a combination of abilities and difficulties which affect the learning process in one or more of reading, spelling and writing. Accompanying weaknesses may be identified in areas of speed of processing, short-term memory, sequencing, auditory and /or visual perception, spoken language and motor skills. It is particularly related to mastering and using written language, which may include alphabetic, numeric and musical notation. Some children have outstanding creative skills, others have strong oral skills. Dyslexia occurs despite normal teaching and is independent of socio-economic background or intelligence. It is, however, more easily detected in those with average or above average intelligence [14].

\subsection{Difficulties that face the dyslexic children in learning}

Children with learning disability usually face trouble in taking information through senses then processing said information to the brain. Sadly, the teaching is yet to serve their needs better. Dyslexia may make a student resistant to conventional teaching methods and the teaching-learning process could be ineffective. In addition, dyslexia are a cause of emotional problems that result from adjustment difficulties such as frustration, anger, low self-esteem and depression. Dyslexic children specifically face the following problems in learning:

1. Tend to make mistakes with the order of letters when spelling a word out.

2. Produce dysphonic spelling errors.

3. Find it challenging to match names to objects and people.

A research by [15] where seven dyslexic students were assessed five of them preferred a visual learning approach. [15] conducted research in which seven dyslexic students were assessed. She found that five of these students preferred a visual learning approach. She also concluded that dyslexic students with writing problems would try to vocalize elements of the word while creating a visual image of it. dyslexic students who have writing problems tend to attempt to vocalise elements of the word (verbal) while also creating a visual image of it (visual).

It is beneficial to use multisensory teaching for dyslexic students [16]. Using information and communication technologies and assistive technologies to learn is helpful for dyslexic students and it enhances the learning process. Thus, increase dyslexic students' motivation to learn. This project's application mitigates the previously mentioned problems in the way it shows the position of the letter in the word, teach

The student each letter with its name and sound as well as shape in different arrangement using combination of media which directly impacts the learning performance. In addition, the application uses VR which provides safe and controlled environment, and high level of interactivity. Moreover, the application does not grade the students' effort as success or fail it supports students with all their attempts through the avatar feature that students interact with and gives a chance of trying again without judgement thereby making the student feel more comfortable and secure. 


\section{Educational Entertainment}

Educational Entertainment also known as Edutainment it's a term that is used to combine education with the entertainment. The first appearance of this term in 1948 was by Walt Disney Company while describing "True Life Adventures series". The series is an animated documentary and that is what made it very popular. Educational entertainment is defined in [17] as any content that is designed to educate and entertain. Many research articles show that education and gaming joined together can provide academic benefits [18]. Educational entertainment goal is to help make the learning experience more intriguing for children because they learn fast while entertained and active [19]. The entertainment comes in form of picture, charts, PowerPoint presentation, videos as well as mobile applications. [20] stated that edutainment is playing a great role in the video games field. For Children, edutainment is a better term than education because children learn fast while they are entertained and active [20].

Before like 10 years ago, all what you can do with your mobile was to call someone or to message him and the most entertaining thing to do with your mobile was to put a new ringtone. Now, and after the growth of using the mobile technology there are hundreds of thousands mobile applications in many multiple categories. This huge growth leads people to use this technology along with the educational field and it's called "M-Learning" [21]. This combination provided a lot of useful mobile applications for children.

The benefits of using the mobile applications to entertain the children and to teach them the languages at the same time according to [20] are: It makes the children remember the language they learn very fast. Games improve the physical, social and emotional skills for children beside the well-known rules help them participate. It makes the children motivated and can participate because of the enjoyable environment. Games support many important skills such as strategic thinking, communication and negotiating skills. This project intended to use the edutainment to help the dyslexic students and other students learn the alphabets in a 360-interactive environment by using VR Technology and Avatar Technology.

\section{$5 \quad$ Virtual Reality}

Virtual Reality (VR) technology is a wide and vast technology. It is applied in many areas such as medical, educational and entertainment. The features of this technology are what enables it to be a great method in treating many issues including Dyslexia. According to Fubini's "People initially use technology to do what they do now - but faster" [22], Virtual reality was developed to get users to replace computer 's keyboard, mouse and joystick with a more interactive and sensory interfaces and thus faster and more involving experience. Virtual reality, Augmented reality, spatial reality, mixed reality, tangible reality and collaborative reality are all synonym for a $3 \mathrm{D}$ environment generated by the computer where the user can be involved in real time and have a sensation of being there [23]. 
Many virtual reality applications adapt the idea of avatar. The use of avatars on the applications is one of the gradual changes that are happening to our world. They are animated computer representation of a user, such as an icon, personal or pictorial representing a person. It is often a three-dimensional shape or a two-dimensional form. It can be expressed as taking shape or personality in the form of a symbolic image in a virtual world and thus achieving the transition from the real world to the virtual digital [24]. In any application when avatar is used for instructions that will be interesting ways instead of reading the instructions by traditional way. In this case, the avatar simulates an environment which is very similar to a real world [25]. These avatars are not necessarily intelligent; they behave in the ways that have been preconfigured in them.

Some people find it difficult to obtain information and lack of access to information as quickly and easily Such as what is required, which can be exacerbated by the lack of methods that give information that is easily accessible and clear. People generally learn better through sources of multimedia information [26]. This is because it contains some effective information such as voice, image and body language. Is easily understood and remembered. Avatar also motivates students to interact longer with educational software and consequently leads to have a significant improvement in the quality of learning [27]. Since they are interacting with students to facilitate learning, they are often animated characters that respond to user actions.

An issue that people with Dyslexia face is the inability to engage in conversations and maintaining them as well, the use of an avatar on VR would help create a comfortable environment for the user, seeing as avatars are mostly used in games to personalize and attract the user. As well as in educational applications where avatar would provide the role of a teacher or mentor thus creating a connection and maintaining the user's attention and interest. All these technologies have potential to help in creating solutions to many problems and have been applied in different applications.

So far, research into the Avatar experience for learning skills and entertainment opportunities among Primary school dyslexic students writing and reading has been limited and this research need to fill this gap. This is in turn will enable the acquisition of automatic knowledge that requires less cognitive effort than traditional educational practices.

\section{Data Collection}

For a complete view and understanding of Dyslexia and its affects, questionnaires were used to collect data concerning the matter. Unstructured interviews with specialists were conducted as well. These interviews helped identify the requirements of the system, Functional Non-Functional, user requirement and system requirements. Each criterion describes the different aspects and needs of the system as a whole. 


\subsection{Questionnaires}

There are many ways in which questionnaires are suitable for this kind of research. First, questionnaires offer a very useful method of generating a broad range of data about the primary characteristics that are under investigation [28]. In addition, they can be readily adapted to the wide variety of subjects and research problems [29]. A further advantage of questionnaires is that they represent cost-effective research approaches because they do not generate interviewer wages and travel costs and, if closed questions are used, do not incur significant data expenses [30].

A survey was conducted in order to investigate the system requirements, with a total of 31 teachers plus 20 parent's respondents. The survey focused on two types of users: parent who has student with dyslexia and special education teacher. The survey has three parts that:

1. Obtain a statement of consent from the respondents to read and agreed to certain terms and conditions.

2. Classify the survey respondents.

3. Identify the needs of the system users (Teacher/ Parent).

The first question in the survey was: Do you prefer the use of technology in education or the traditional way? As result of this question, more than $80 \%$ of the teachers sees the effectiveness of using e-learning in teach. When asked about most problems facing students with learning disabilities, $74.2 \%$ confirmed that they have difficulty in reading, $54.8 \%$ have difficulty in writing, while $54.8 \%$ have difficulty in Mathematics. We asked the teachers about the most effective way for teaching students with dyslexia, $61.3 \%$ confirmed that use of entertainment and technology, $22.6 \%$ recursive training and learning at home, while $16.1 \%$ state that the focus on Arabic more than other subjects in education will help the students with dyslexia. when asked teacher about student with learning disabilities, confirmed that:

- The help provided by the school for the students with dyslexia sometimes is not enough to enhance their learning process besides the family need to but more intention to their dyslexic students.

- High approval that child skills can be developed through use on educational application in mobile phone.

- Strong approve for the effectiveness of displaying the image and pronunciation at the same time.

When asked about technology and children with learning disabilities, confirmed that:

- The high incidence of children who stumbles when reading long words

- About the child knows the difference between the positions of letters in the word, there was a convergence of proportions between sometimes and not.

- About the child write letters backwards, there was a convergence of proportions between sometimes and yes, but the high percentage is they do not write the word back word. 
When asked about education and children with learning disabilities, confirmed that:

- Attention in schools it is enough to help them, there was a convergence of proportions between sometimes and not.

- Strong disagreement for traditional learning, and it is not enough to help them

- Many parents' approval that the use of e-learning technologies increases the effectiveness of learning.

When asked about technology and children with learning disabilities, confirmed that:

- Nowadays, most of children use mobile phones. In addition, there is a strong approve for the effectiveness of displaying the image and pronunciation at the same time.

- Strong approval that child skills can be developed through the use of educational application in mobile phone.

\subsection{User interviews}

In order to collect the requirements and to understand the need for dyslexic students we interviewed the specialists: We interviewed (a) special education supervisor. He works as an Assistive Technology manager at the Technical Assistance Centre for teaching the disabled. He mentioned that: the students with learning disability are not mentally retarded or has trouble with any of their five senses. Their disability is associated with the cognitive processes that is related to their five senses, by that I mean they have issues with the visual processing not with their sight. In addition, autistic students as a different case of the disabled need activities that stimulate their senses and your application can help them with that. We are about to establish a centre for assistive technology, and we need an application that helps the dyslexic.

We asked (b) an autism teacher, she clarified that: they have cases where the students find it difficult to differentiate between the Arabic alphabets letter in initial word form, middle and final form, moreover some of the students has trouble connecting a number with its significance. Furthermore, some students hesitate to start a simple conversation like saying hello, how are you, or I need help.

A special education specialist supervisor (c) at the centre for the disabled, mentioned that: students at the centre have difficulties linking a picture to its right word, in addition they have troubles differentiating between the Arabic alphabets letter in initial word form, middle and final form.

A special education specialist (d): stated that, they make the best use of the technology in education, I have this autistic kid in the centre and she can write the alphabets and words by using an iPad, even though she is an autistic which is less capable than the other learning disabilities.

Learning methods from a child to another may vary and what works well with one child may not work with the others. Moreover, with the new era of technology and the increasing use of smartphones and tablets many children will like the technology- 
based approaches, when creating this approach, you must consider the differences and difficulties they have and add certain features like repeat and skip. These important features were highlighted by a special education supervisor (e).

After collecting the requirement from teachers and parents using two different methods questionnaires and interview, the specification of the application has been finalized. In this paper no technical details will be discussed. Therefore, a storyboard of the final application will be shown below in figure 1. Technical details will be discussed on future paper.

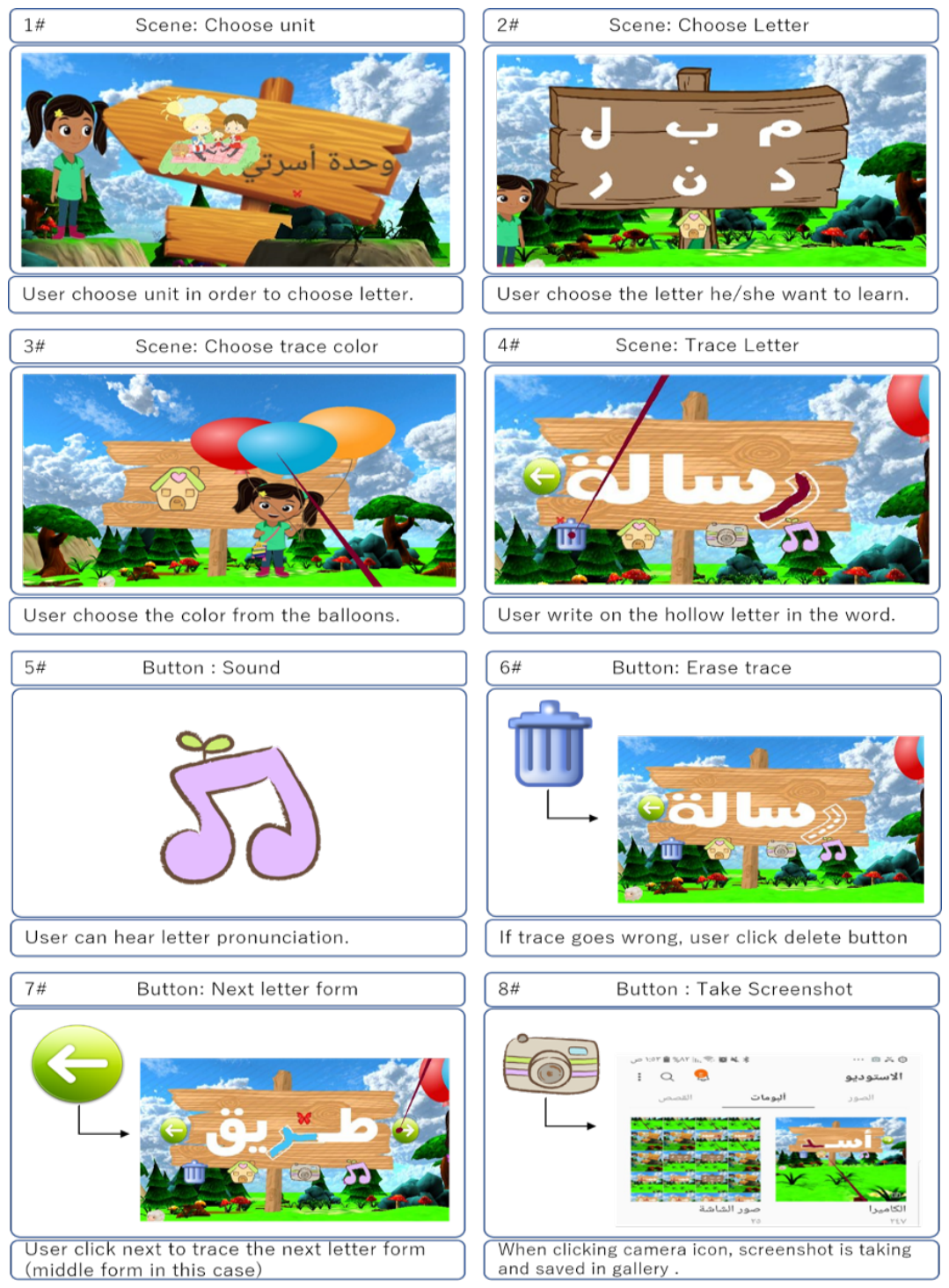

Fig. 1. Story board 


\section{$7 \quad$ Procedure and Results}

In order to estimate the effectiveness of the proposed application, two different learning experience were designed. The first learning experience (version 1) is the proposed application of this study. The other (version 2) is the traditional learning experience. Moreover, we conducted all of experiments with (10) children aged 6-7 years and we have already taken their parents' approval for performing these experiments. The following describes the steps of the experiment:

1. The student cohort was randomly split into two groups, group A and group B. There were 5 learners in each group.

2. Two lessons were examined in the proposed application, the first is on "B letter in Arabic" (course 1) and the second is "N letter in Arabic" (course 2). These were used as revision lessons: that is the students were taught these subjects in previous classes.

3. The first group of students (group A) is given access to the "B letter in Arabic" course that has been delivered to them using version 1 of the system. The second group (group B) has the same course but delivered to them using version 2 of the system.

4. The first session of the experiment was the same for all learners in both groups. This session included a brief explanation of the study, familiarization with the system and familiarity with the concept of two courses.

5. Other sessions contained interaction with the two learning experiences.

6. Viewing the lesson, the students chose to access the "B letter in Arabic" course. What they see will be determined by the version of the system. Hence, those using version 1 will see the course interface presented in Figure 2, whilst those students using version 2 will see what shown in Figure 3.

7. During the experiment, the two groups were observed by their teacher using group observation techniques.

8. After finishing, the second course " $\mathrm{N}$ letter in Arabic" is made available. In the "N letter in Arabic" course, group A is given access to the content delivered to them using version 2, whilst group B delivered to them using version 1 .

9. The students' progress through the lesson as described above and the same evaluation procedure is applied.

The approach employed to assess the two systems consisted of a crossover experiment through which both groups of participants were subjected to both systems. The purpose of this was to ensure that any perceived differences in the results were not due to the composition of the students in the group. 

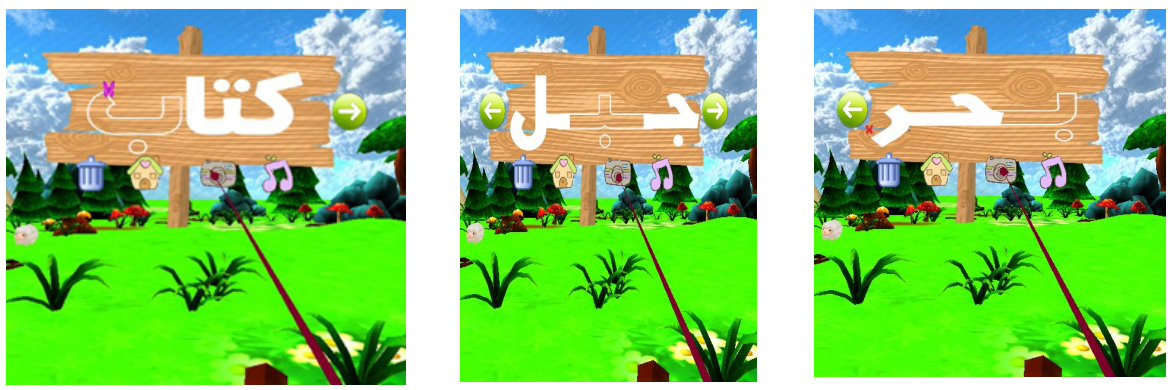

Fig. 2. The first learning experience (Version 1)

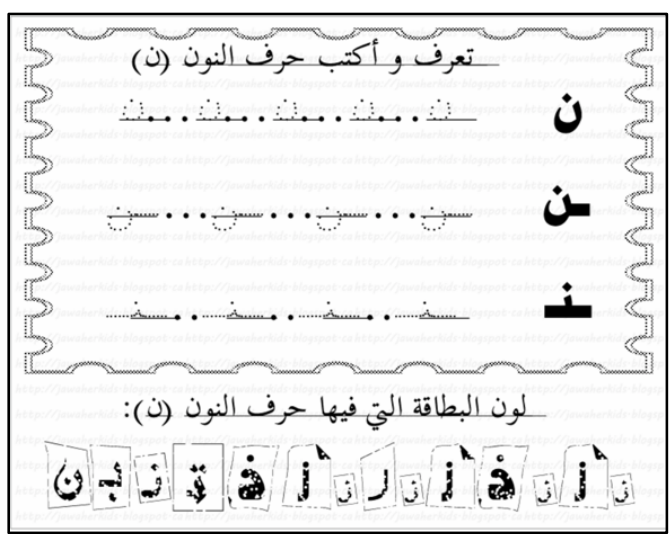

Fig. 3. The first learning experience (version 2)

Through the nonparticipant observation above - an observation where the observer is not involved directly in the situation to be observed - of the group, the results were as follows:

Students found the explanation and demonstration of how the app works clear and understandable. For some students there was a bit of difficulty at first seeing it was a new experience but after some tries, they got comfortable and overcame that issue and enjoyed the experience. As students were eager to try the app there was a slight competition of whose turn it was. Also, they wanted to use/ play for a while longer, there was even a student from outside the group that was intrigued and asked to join and take a turn. The students understood the purpose of the icons within the app clearly and did not face trouble locating and using them correctly. Overall, the students' emotional state was happy and entertained as well as interested and focused. In the end when the students were asked on the app, they answered with enthusiasm and joy, there was a student that complimented the environment specifically and how it cheered her up. 


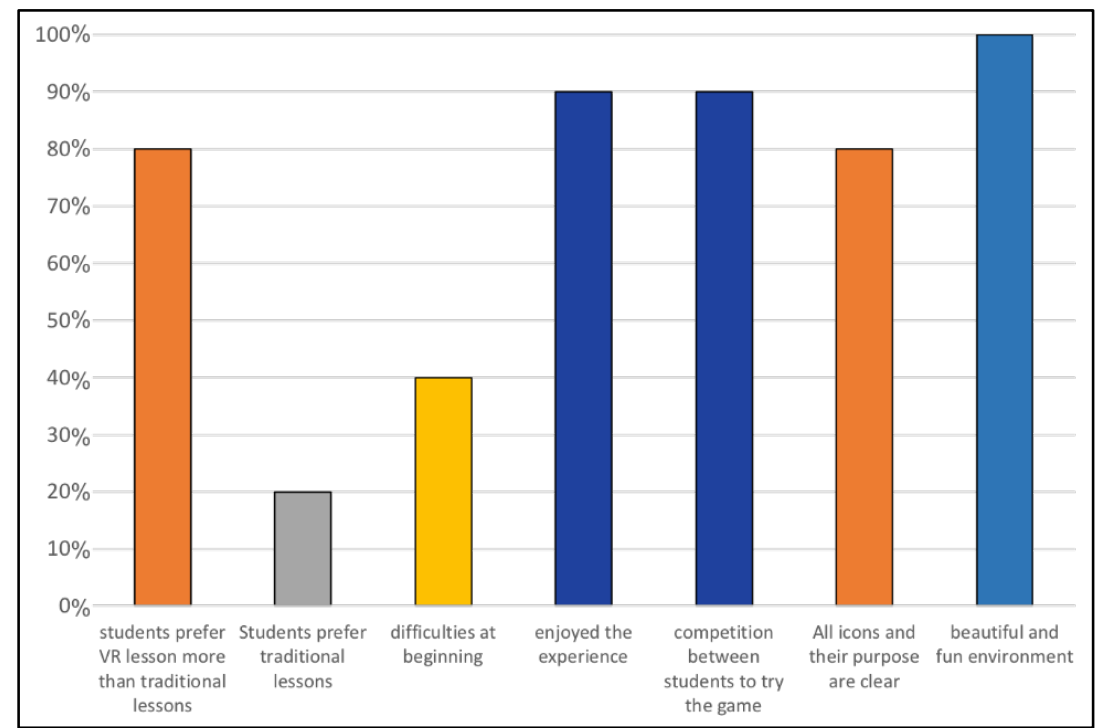

Fig. 4. Learners' satisfaction through eliciting learners' opinion about different aspects of the system

\section{Conclusion}

The project described what the dyslexia is, what are the problems that the dyslexic children face in learning and how can this system support them by solving their problems of learning the Arabic alphabets in an interesting way by using the (Edutainment) that mix the education along with the entertainment for a better learning experience and this will be achieved by using the virtual reality technology that gives the students a 3D-interactive environment and the avatar technology that provides the effective information such as the body language, the voice and the images. It was challenging that the dyslexic students would love using the technology and mobile applications in learning but, according to the survey that's been sent to the learning disabilities' parents there was a great approval that their children's skills can be developed by the use of the educational applications. Thus, the proposed system is a free mobile application that is specialized in teaching the dyslexic students the Arabic alphabets with the VR headset by letting the avatar pronounce the letter they want to learn, let them trace the same letter by the controller in all its situations to let them differentiate between them and send their tracing progress to their teachers for the evaluation.

\section{Acknowledgement}

Special thanks go to the schools and the students for making this study possible by providing their valuable contribution to validate the proposed application. 


\section{References}

[1] British Dyslexia Association, 2007. An Overview of Dyslexia. Retrieved July 12, 2020 from https://www.bdadyslexia.org.uk/dyslexia/about-dyslexia/what-is-dyslexia

[2] _Beacham, N. A., and Alty, J. L., 2006. An investigation into the effects that digital media can have on the learning outcomes of individuals who have dyslexia. Computers \& Education, 47(1), 74-93. https://doi.org/10.1016/j.compedu.2004.10.006

[3] Cheek, J., Abrams, E.M., Lipschitz, D.L., Vago, D.R. and Nakamura, Y., 2017. Creating novel school-based education programs to cultivate mindfulness in youth: What the letters told us. Journal of Child and Family Studies, 26(9), pp.2564-2578. https://doi.org/10.1007/ s10826-017-0761-1

[4] World Health Organization., 2020. Definition: intellectual disability. Retrieved July 12, 2020 from https://www.euro.who.int/en/health-topics/noncommunicable-diseases/mentalhealth/news/news/2010/15/childrens-right-to-family-life/definition-intellectualdisability\#: :text=Intellectual\%20disability $\% 20$ means $\% 20 \mathrm{a} \% 20$ significantly, $\mathrm{a} \% 20$ lasting $\% 20$ effect $\% 20$ on $\% 20$ development.

[5] Govindaraju, M., 2019. Understanding dyslexia and multiple intelligences. Learning Curve, (5), pp.51-56.

[6] Hoien, T. and Sundberg, P., 2000. Dyslexia: From theory to intervention (Vol. 18). Springer Science \& Business Media.

[7] Bishop, D.V. and Snowling, M.J., 2004. Developmental dyslexia and specific language impairment: Same or different? Psychological bulletin, 130(6), p.858. https://doi.org/ 10.1037/0033-2909.130.6.858

[8] Alsobhi, A.Y., Khan, N. and Rahanu, H., 2014, July. Toward linking dyslexia types and symptoms to the available assistive technologies. In 2014 IEEE 14th International Conference on Advanced Learning Technologies (pp. 597-598). IEEE. https://doi.org/10.11 09/icalt.2014.174

[9] Vellutino, F.R., Fletcher, J.M., Snowling, M.J. and Scanlon, D.M., 2004. Specific reading disability (dyslexia): What have we learned in the past four decades? Journal of child psychology and psychiatry, 45(1), pp.2-40. https://doi.org/10.1046/j.0021-9630.2003.00305.x

[10] Maybury, M., 2001. Intelligent interfaces for universal access: challenges and promise. Human- Computer Interaction - HCI, Seattle, Washington, USA.

[11] Woodfine, B.P., Nunes, M.B. and Wright, D.J., 2008. Text-based synchronous e-learning and dyslexia: Not necessarily the perfect match! Computers \& Education, 50(3), pp.703717. https://doi.org/10.1016/j.compedu.2006.08.010

[12] Riddick, B., 1996, Living with Dyslexia. London: Routledge.

[13] International Dyslexia Association. (2002). What Is Dyslexia?, Retrieved July 12, 2020 from http://www.interdys.org/FAQWhatIs.ht https://doi.org/10.1002/dys.1459

[14] Ott, P., 2007., Teaching children with dyslexia: A practical guide. Routledge.

[15] Exley, S., 2003, The effectiveness of teaching strategies for students with dyslexia based on their preferred learning styles. British Journal of Special Education, 30 (4), 213-220. https://doi.org/10.1111/j.0952-3383.2003.00313.x

[16] Scott, R. and Snowling, M.J., 2004. Dyslexia and counselling. London: Whurr.

[17] Slater, M.D. and Rouner, D., 2002. Entertainment - education and elaboration likelihood: Understanding the processing of narrative persuasion. Communication theory, 12(2), pp.173-191. https://doi.org/10.1111/j.1468-2885.2002.tb00265.x

[18] Granic, I., Lobel, A. and Engels, R.C., 2014. The benefits of playing video games. American psychologist, 69(1), p.66. https://doi.org/10.1037/a0034857 
[19] Korkmaz, Ş.Ç., 2013. Language games as a part of edutainment. Procedia-Social and Behavioral Sciences, 93, pp.1249-1253. https://doi.org/10.1016/j.sbspro.2013.10.023

[20] Egenfeldt-Nielsen, S., 2011. Beyond edutainment: exploring the educational potential of computer games, IT-University Copenhagen.

[21] Godwin-Jones, R., 2011. Mobile apps for language learning. Language Learning \& Technology, 15(2), pp.2-11.

[22] Velliotis, E.P., 2008. Classroom culture and dynamics. Nova Publishers.

[23] McMenemy, K. and Ferguson, R.S., 2007. A hitchhiker's guide to virtual reality. CRC Press.

[24] Britt, A., 2008. Avatar. New York Times Magazine, 10.

[25] Sayre, S. and King, C., 2010. Entertainment and society: Influences, impacts, and innovations. Routledge.

[26] Chittaro, L. and Ranon, R., 2007. Web3D technologies in learning, education and training: Motivations, issues, opportunities. Computers \& Education, 49(1), pp.3-18. https://doi.org/ 10.1016/j.compedu.2005.06.002

[27] Foster, A.L., 2008. Using Second Life as a platform for education: Professor Avatar. The education digest, 73(5), p.12.

[28] Williamson J. B., Karp D. A., Dalphin, J. R. and Gray, P. S., 1982, The research craft: introduction to social research methods, London: Little, Brown.

[29] Wright, D., 2001. Nursing students with dyslexia: WWW support - an ongoing project. Journal of the Britsih Computer Society's Nursing Specialist Group, 13(1): 18-22.

[30] Browder, D.M., Spooner, F. and Courtade, G.R., 2020. Teaching students with moderate and severe disabilities. Guilford Publications.

\section{Authors}

Esraa Maskati, Fatimah Alkeraiem, Nada Khalil, Raha Baik and Rawan Aljuhani work for Taibah University in Saudi Arabia. They can be contacted through esraa.1695@gmail.com, fatimah.alkeraiem@gmail.com, nada.imkhalil@gmail.com, raha.baik @.gmail.com, aljohanirawan@gmail.com respectively.

Aisha Alsobhi works for King Abdulaziz University in Saudi Arabia ayalsobhi@kau.edu.sa

Article submitted 2020-11-04. Resubmitted 2020-12-13. Final acceptance 2020-12-15. Final version published as submitted by the authors. 